\title{
The relationship between dioxins and salivary steroid hormones in Vietnamese primiparae
}

\author{
Ho Dung Manh $\cdot$ Teruhiko Kido $\cdot$ Rie Okamoto $\cdot$ Sun XianLiang $\cdot$ Nguyen Hoang Viet $\cdot$ Madoca Nakano \\ Pham The Tai - Shoko Maruzeni $\cdot$ Muneko Nishijo $\cdot$ Hideaki Nakagawa $\cdot$ Hiroyuki Suzuki $\cdot$ Seijiro Honma • \\ Dao Van Tung $\cdot$ Dang Duc Nhu $\cdot$ Nguyen Ngoc Hung $\cdot$ Le Ke Son
}

Received: 20 June 2012 / Accepted: 9 October 2012 / Published online: 2 November 2012

(C) The Japanese Society for Hygiene 2012

\begin{abstract}
Objective Nearly 40 years after Agent Orange was last sprayed, we conducted a cross-sectional study to evaluate the impact of dioxin exposure on salivary hormones in Vietnamese primiparae. Our previous studies found higher levels of salivary cortisol and cortisone in one of the most highly dioxin-contaminated areas, known as a "hot-spot", than in a non-exposed area. As a result, we suggested that further research with a larger number of participants would be needed to confirm whether dioxin affects steroid hormone levels in Vietnamese primiparae.

Methods The concentration of steroid hormones in saliva was determined by liquid chromatography (electrospray ionization tandem mass spectrometry), whereas the concentrations of polychlorinated dibenzo-p-dioxins (PCDDs) and dibenzofurans (PCDFs) in breast milk were determined by gas chromatography-high resolution mass spectrometry,
\end{abstract}

H. D. Manh · S. XianLiang · N. H. Viet - M. Nakano

Division of Health Sciences, Graduate School of Medical

Science, Kanazawa University, 5-11-80 Kodatsuno,

Kanazawa, Japan

e-mail: manhhodung@yahoo.com

H. D. Manh

Faculty of Environmental Engineering and Biotechnology,

Lac Hong University, No. 10 Huynh Van Nghe,

Buu Long, Bien Hoa, Dong Nai, Vietnam

T. Kido $(\bowtie) \cdot$ R. Okamoto

Faculty of Health Sciences, Institute of Medical

Pharmaceutical and Health Sciences, Kanazawa University,

5-11-80 Kodatsuno, Kanazawa, Ishikawa, Japan

e-mail: kido@mhs.mp.kanazawa-u.ac.jp

P. T. Tai · S. Maruzeni $\cdot$ M. Nishijo $\cdot$ H. Nakagawa Department of Public Health, Kanazawa Medical University,

1-1 Daigaku, Uchinada, Ishikawa, Japan for a sample of the population from a "hot-spot" $(n=16)$ and a non-exposed area $(n=10)$. All subjects were aged between 20 and 30 years and had children aged between 4 and 16 weeks.

Results The mean toxic equivalence of PCDDs, PCDFs and PCDDs + PCDFs in breast milk in the hot-spot area was found to be significantly higher than in the nonexposed area $(p<0.001)$. Likewise, salivary cortisol, cortisone and dehydroepiandrosterone (DHEA) levels were significantly higher in the hotspot area than in the nonexposed area $(p<0.05)$. As a result, herein we report, for the first time, that salivary DHEA levels in primiparae are higher in a hot-spot than in a non-exposed area, and that this may be the result of dioxin exposure.

Conclusions Our findings highlight the long-term effects of Agent Orange/dioxin on steroid hormones in Vietnamese primiparae in the post-war period.

\section{H. Suzuki}

Department of Life and Health Sciences, Chubu University, 1200 Matsumoto, Kasuga, Aichi, Japan

S. Honma

ASKA Pharma Medical Co. Ltd.,

5-36-1 Shimosakunobe, Kawasaki, Japan

D. Van Tung

Department of Biochemistry, Viet Tiep Hospital Hai Phong, No.1 Nha Thuong Street, Hai Phong, Vietnam

D. D. Nhu $\cdot$ N. N. Hung

10-80 Division, Hanoi Medical University,

No. 1 Ton That Tung, Dong Da, Hanoi, Vietnam

L. K. Son

Environment Administration, Ministry of Natural Resources and Environment, 67 Nguyen Du Street, Hanoi, Vietnam 
Keywords Dioxin $\cdot$ Breast milk $\cdot$ Saliva $\cdot$ Steroid hormone $\cdot$ Vietnam

\section{Introduction}

There is growing concern regarding the adverse health effects posed by endocrine disrupting chemicals (EDCs) in the environment that may interfere with hormone biosynthesis and metabolism, thereby disrupting normal homeostasis [1, 2]. In this respect, some of the most ubiquitous environmental toxicants known to act as EDCs, namely dioxins, have attracted considerable interest in recent years.

Dioxins, especially polychlorinated dibenzo- $p$-dioxins (PCDDs), polychlorinated dibenzofurans (PCDFs), and polychlorinated biphenyls (PCBs), are environmentally persistent organic pollutants (POPs) generated by industrial and domestic waste-incineration processes and during herbicide manufacture. Due to their high lipophilicity, dioxins tend to accumulate in fatty tissue. As a result, their concentration increases as they migrate up the food chain, where they eventually enter humans upon consumption of contaminated food. Breast milk samples have been found to contain very high levels of these compounds and have therefore been used to monitor dioxin exposure in humans [3].

During Operation Ranch Hand (1961-1972), the US military sprayed millions of liters of Agent Orange south of the former demilitarized zone at the 17th parallel for defoliation and crop destruction in Southern Vietnam. Unfortunately, Agent Orange was contaminated with 2,3,7,8-tetrachlorodibenzo-p-dioxin (TCDD), the most toxic chemical in the dioxin family, with around $366 \mathrm{~kg}$ of this chemical thought to have been released [4]. Although the dioxin levels in sprayed areas in Vietnam are currently much lower due to tropical rain, erosion, and chemical breakdown over the past 40 years, their level in soil and breast milk is still higher than in non-exposed areas [5-8]. However, the most heavily contaminated areas are former US airbases, where Agent Orange was spilled and sprayed intensively around the perimeter, etc. These areas are known as "hot-spots" [9], with the three most important being found in Bien Hoa, Phu Cat, and Da Nang [10, 11].

Although many Vietnamese were exposed to a greater extent, most studies concerning the effects of Agent Orange on human health carried out to date have focused on American veterans (Institute of Medicine, update 2008). As the health consequences of dioxin contamination are more likely to be found in Vietnam than in any other population, this country provides a unique setting for dioxin studies [12-15].
Dioxins are known to be involved in the pathogenesis of cancer [16], diabetes [17], and reproductive abnormalities [18]. Furthermore, numerous experimental studies have shown that they also interfere with the hormonal system. The pituitary gland appears to be a target organ for dioxin, with exposure disrupting the normal feedback mechanisms between plasma testosterone, dihydrotestosterone, estradiol, and luteinizing hormone secretion [19]. TCDD decreases the bioactivity of adrenocorticotropic hormone (ACTH), thereby resulting in altered levels of circulating corticosterone [20]. In a recent study, polychlorinated biphenyl 126 (PCB 126) was found to induce differential changes in androgen, cortisol, and aldosterone biosynthesis in human adrenocortical H295R cells [21].

Although numerous studies concerning the effect of dioxins on steroid hormones have been undertaken both in vitro and in vivo, very few of these involved human subjects. Previous studies [22, 23] of a subgroup of primiparae from a hot-spot and a non-exposed area found that the level of salivary cortisol and cortisone were higher in the hot-spot than the non-exposed area in Vietnam. In this study, the number of subjects was increased in order to confirm the effects of dioxin exposure on steroid hormone levels in Vietnamese primiparae.

\section{Materials and methods}

\section{Study area}

The study areas are shown in Fig. 1. The hot-spot is Phu Cat Airbase, which was an important US military airbase and a Ranch Hand site during the Vietnam War. Indeed, records indicate that 17,000 drums of Agent Orange, 9000 drums of Agent White, and 2900 drums of Agent Blue were stored there [24]. The airbase is located in Binh Dinh province, in southern Vietnam, and is currently used for both civilian and military purposes. Herbicide storage, loading, and plane washing has been confirmed at Phu Cat, where run-off from the herbicide wash area eventually enters a series of small lakes used by local inhabitants to raise fish and waterfowl. The Hatfield Consultancy (2009) has reported a maximum TCDD level of $236,000 \mathrm{pg} / \mathrm{g}$ TCDD in soil taken from close to Phu Cat, which is much higher than the internationally accepted standard of 1000 ppt TCDD in soils.

The non-exposed area is Kim Bang district, which is located in Ha Nam province in the north of the country. This site was chosen as the control area because it was not sprayed with herbicide during the war. Both areas are rural and have not been affected by industrial pollution. 


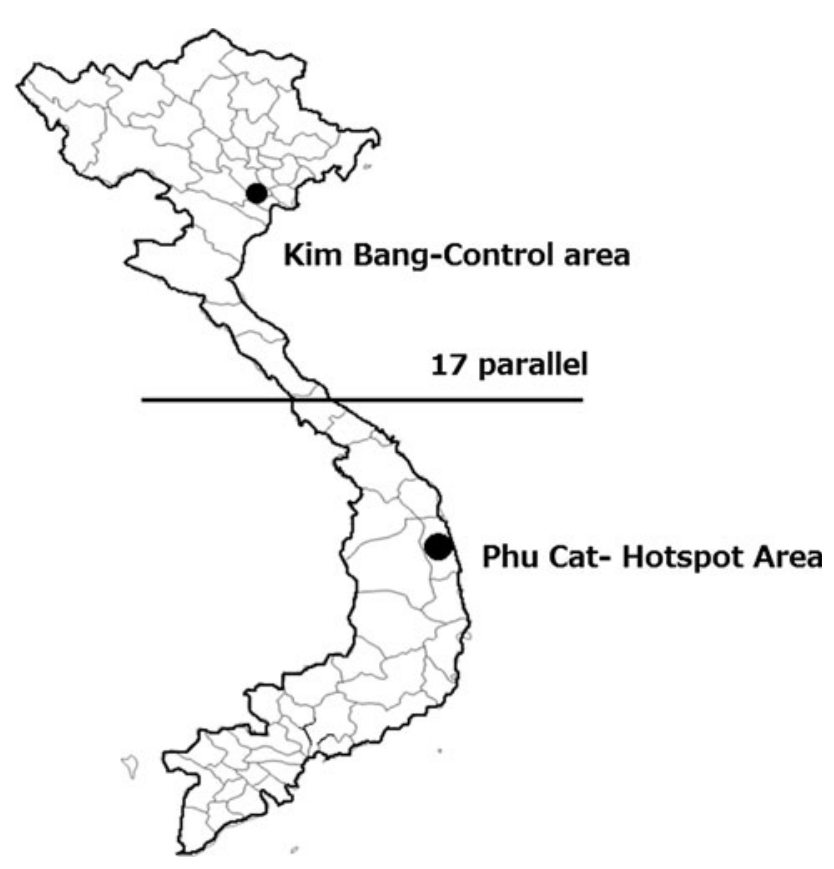

Fig. 1 Map of Vietnam and study areas

Participants and sample collection

Lactating primiparous women aged between 20 and 30 years and with children aged between 4 and 16 weeks were recruited for this study. After the local authorities and medical staff had explained the purpose of the study, 16 participants living in several communities located approximately 3-6 km from Phu Cat Airbase, and 10 from the non-exposed area, agreed to participate. Breast milk and saliva samples were collected in the morning, between 8 and 10 AM, in September 2008. The temperature in both areas was around $30-34{ }^{\circ} \mathrm{C}$ at that time. The participants collected $10-20 \mathrm{~mL}$ of breast milk and $2-3 \mathrm{~mL}$ of saliva by themselves, with support from trained medical staff. Saliva was collected by rinsing the mouth with water then transferring the resulting mixture directly into a Bakelite test tube $(15 \mathrm{~mL})$. All samples were collected in chemically cleaned containers and frozen in dry ice over several days. These samples were then transported by airplane to Japan and stored at $-70{ }^{\circ} \mathrm{C}$ until analysis. Participants were interviewed about their age, family income, residence period, occupation, education, disease, and any therapy related to hormone metabolism. Although various kinds of job were reported, the main jobs in the hot-spot area were service industry $(31 \%)$, teachers $(19 \%)$, or official workers $(13 \%)$, whereas those in the non-exposed area were service industry (33\%), agriculture (33\%), and manual labor (22\%). Furthermore, the hot-spot area had a higher educational level, with some mothers (19\%) having graduated from university; no mother had graduated from university in the non-exposed area. Their body height and weight were also measured to calculate the body mass index (BMI).

The purpose of the present study was explained thoroughly, and written informed consent was obtained from each participant via their local people's authorities committee. This study was approved by the Medical Ethics Committee of Kanazawa University (Permission No. Health-89).

Salivary hormone analysis

Cortisol- ${ }^{2} \mathrm{H}_{3}$ (F-d4, $1 \mathrm{ng}$ ), DHEA- ${ }^{2} \mathrm{H}_{3}$ (DHEA-d4, $100 \mathrm{pg}$ ), testosterone- ${ }^{2} \mathrm{H}_{3}$ (T-d3, $100 \mathrm{pg}$ ), estradiol- ${ }^{13} \mathrm{C}_{4}$ (E2- ${ }^{13} \mathrm{C}_{4}$, $100 \mathrm{pg}$ ), and progesterone- ${ }^{13} \mathrm{C}_{3}\left(\mathrm{P} 4-{ }^{13} \mathrm{C}_{3}, 100 \mathrm{pg}\right)$ were added to the saliva $(1-2 \mathrm{~mL})$ as internal standards and the hormones extracted with ethyl acetate. The extract was applied to a Bond Elut C18 cartridge column to separate the polar (cortisol and cortisone) and less-polar (estrogen, progesterone, and androgen) steroid fractions. The polar fraction was then quantified directly by liquid chromatography-tandem mass spectrometry (LC-MS/MS) following a previously reported method [25]. The less-polar fraction was applied to an ion-exchange cartridge column to fully separate estradiol from androgen and progesterone. After derivatization, the estradiol fraction was assayed by LC-MS/MS following a previously described method [26]. The androgen/progesterone fraction was derivatized with picolinoyl ester and assayed by LC-MS/MS [27]. The lower analytical limits for cortisol, cortisone, DHEA, androstenedione, testosterone, estradiol, and progesterone were $50,50,2,10,1,0.1$, and $10 \mathrm{pg} /$ assay, respectively.

Analysis of dioxin in breast milk

Breast milk samples were analyzed following previously reported methods [7, 28]. Thus, after extraction of the fat from $10 \mathrm{~g}$ of breast milk, $40-80 \mathrm{pg}$ of $17-{ }^{13} \mathrm{C}_{12}$-labeled PCDD/PCDF congeners was spiked as an internal standard. A series of purification operations consisting of alkali digestion and chromatography on a multi-layer silica gel column and an active carbon-dispersed silica gel column were carried out to separate and collect the PCDDs/PCDFs. The final sample extract was evaporated to dryness under a nitrogen stream, and then re-dissolved by addition of $20 \mu \mathrm{L}$ of nonane containing $40 \mathrm{pg}$ of ${ }^{13} \mathrm{C}_{12}-1,2,3,4$-TCDD and ${ }^{13} \mathrm{C}_{12}-1,2,7,8$-TCDF as external standards.

Final determination was carried out using a gas chromatograph (GC: HP-6980, Hewlett-Packard, Palo Alto, CA) equipped with a high-resolution mass spectrometer (HRMS: JEOL MS station-JMS700). Analyses were performed in the selected ion-monitoring mode (SIM) at a resolution of 10000. Seventeen PCDD/PCDF congeners were calculated on a lipid basis, then converted to toxic 
equivalents (TEQ) using the international World Health Organization (WHO) toxicity equivalency factors (TEFs) 2005 [29].

Quality control and quality assurance were implemented following guidelines described in the Japanese Industrial Standard (JIS). Eligibilities for dioxin analysis were certified by using natural reference powder milk CRM607 provided by the European Commission. The recovery rate was typically in the range 60-95 \% and the detection limits determined at a signal-to-noise ratio of $3(S: N=3: 1)$ on a lipid basis. Values for the congener concentrations below the detection limits were set to half the detection limits.

\section{Statistical analysis}

Data are shown as the median (interquartile range). The mean difference of each indicator between two areas was calculated by applying either Student's $t$-test or the MannWhitney $U$ test, depending on their distribution, as judged by a Shapiro-Wilk test. The least-squares regression method was used to fit the quadratic curve, and the statistical significance was calculated using the $F$ test for the effectiveness of the model. The significance level was set to $p<0.05$. All statistical analyses were performed using the JMP ${ }^{@} 9$ software package (SAS Institute, Japan).

\section{Results}

Participant's characteristics

Table 1 shows the main characteristics of the study participants. There were no significant differences between the participants for the two areas in terms of age, height,

Table 1 Comparison of participant characteristics between the hot-spot and non-exposed areas

\begin{tabular}{|c|c|c|c|}
\hline & $\begin{array}{l}\text { Hot-spot } \\
(n=16)\end{array}$ & $\begin{array}{l}\text { Non-exposed } \\
\text { area }(n=9)\end{array}$ & $p$ value \\
\hline Age (years) & $25(21.5-27.8)$ & $20(19-25)$ & $0.054^{\mathrm{a}}$ \\
\hline Height $(\mathrm{cm})$ & $150.2(148.2-156.7)$ & $152.5(150.3-155.7)$ & $0.51^{\mathrm{b}}$ \\
\hline Weight (kg) & $46.3(45.0-50.4)$ & $48.5(44.8-51.0)$ & $0.81^{\mathrm{a}}$ \\
\hline BMI $\left(\mathrm{kg} \mathrm{m}^{-2}\right)$ & $20.4(20.0-21.6)$ & $20.6(19.8-21.3)$ & $0.93^{\mathrm{b}}$ \\
\hline $\begin{array}{l}\text { Family income } \\
\left(\times 10^{4} \text { VND/ }\right. \\
\text { month })\end{array}$ & $200(163-375)$ & $200(75-300)$ & $0.19^{\mathrm{a}}$ \\
\hline $\begin{array}{l}\text { Residence } \\
\text { period } \\
\text { (years) }\end{array}$ & $24(20.3-27.8)$ & $20(19-25)$ & $0.13^{\mathrm{a}}$ \\
\hline
\end{tabular}

Data are shown as median (inter-quartile range)

a Student's $t$ test

b Mann-Whitney $U$ test weight, BMI, family income, or residence period. The mean age and residence period in each area were very similar, with most participants having lived there since they were born. The family income for the two areas reflects their living conditions, which are similar for both rural areas.

Concentration of dioxin in breast milks

Table 2 shows the dioxin levels in breast milk for the two areas. The median total toxic equivalence (TEQ) of PCDDs, PCDFs, and PCDDs + PCDFs in breast milk in the hot-spot area was 9.7, 5.8, and $16.1 \mathrm{pg}-\mathrm{TEQ} / \mathrm{g}$ lipid $(3.3,1.9$, and $5.2 \mathrm{pg}-\mathrm{TEQ} / \mathrm{g}$ lipid in the non-exposed area), respectively, thus meaning that the values in the former are almost three times higher than in the latter $(p<0.001)$.

Concentration of salivary steroid hormones

Table 3 shows the salivary steroid hormone levels for the two areas. The levels of three out of seven steroid hormones, namely cortisol, cortisone, and DHEA, can be seen to be significantly higher in the hot-spot area than in the non-exposed area $(p<0.05)$. There was no significant difference in terms of androstenedione, estradiol, progesterone, or testosterone level, although estradiol tended to be lower in the hot-spot area $(p=0.063)$.

Relationship of dioxin and salivary steroid hormones

Figure 2 shows the relationship between salivary steroid hormones and the total TEQ of PCDDs + PCDFs for the two areas together. The inverted U-shaped relationship between salivary cortisol or cortisone and the TEQ dioxin levels in breast milk can clearly be observed. The cortisol and cortisone levels were highest at a dioxin concentration of around 10-15 pg-TEQ/pg lipid. Furthermore, salivary DHEA also showed an inverted U-shaped relationship with dioxin in breast milk, reaching a maximum at a TEQ dioxin level of around 13-18 pg-TEQ/pg lipid.

In contrast, the relation between estradiol and TEQ of PCDDs + PCDFs in breast milk was U-shaped, with the lowest estradiol level being observed at a dioxin concentration of around 13-19 pg-TEQ/pg lipid.

\section{Discussion}

Salivary steroid hormones, including cortisol, cortisone, and especially DHEA, have been found to be significantly higher in a hot-spot than in a non-sprayed area in Vietnam. 
Table 2 Comparison of dioxin levels in breast milk between the two areas
Data are shown as median (inter-quartile range)

a Student's $t$ test

b Mann-Whitney $U$ test

\begin{tabular}{|c|c|c|c|}
\hline Congener & Hot spot $(n=16)$ & Non-exposed area $(n=9)$ & $p$ value \\
\hline \multicolumn{4}{|c|}{ PCDD congeners (pg/g lipid) } \\
\hline $2,3,7,8-\mathrm{TeCDD}$ & $2.1(1.3-2.6)$ & $1.0(0.7-1.2)$ & $<0.0001^{\mathrm{a}}$ \\
\hline 1,2,3,7,8-PeCDD & $5.7(3.8-7.8)$ & $1.8(1.6-2.0)$ & $<0.0001^{\mathrm{a}}$ \\
\hline $1,2,3,4,7,8-\mathrm{HxCDD}$ & $2.5(2.0-3.3)$ & $0.8(0.6-1.0)$ & $<0.0001^{\mathrm{a}}$ \\
\hline $1,2,3,6,7,8-\mathrm{HxCDD}$ & $10.0(7.7-11.3)$ & $1.6(1.5-2.2)$ & $<0.0001^{\mathrm{a}}$ \\
\hline $1,2,3,7,8,9-\mathrm{HxCDD}$ & $3.4(2.7-4.3)$ & $0.9(0.6-1.1)$ & $<0.0001^{\mathrm{a}}$ \\
\hline 1,2,3,4,6,7,8-HpCDD & $17.1(12.6-19.8)$ & $2.9(2.5-3.7)$ & $<0.0001^{\mathrm{b}}$ \\
\hline OCDD & $80.9(52.4-101)$ & $14.8(11.5-17.0)$ & $<0.0001^{\mathrm{b}}$ \\
\hline \multicolumn{4}{|l|}{ PCDF congeners (pg/g lipid) } \\
\hline $2,3,7,8-\mathrm{TeCDF}$ & $0.7(0.5-0.9)$ & $0.8(0.5-1.0)$ & $0.36^{\mathrm{a}}$ \\
\hline $1,2,3,7,8-\mathrm{PeCDF}$ & $2.4(1.4-3.2)$ & $0.5(0.3-0.7)$ & $<0.0001^{\mathrm{a}}$ \\
\hline $2,3,4,7,8-\mathrm{PeCDF}$ & $7.6(6.5-9.8)$ & $3.9(3.6-5.0)$ & $<0.0001^{\mathrm{a}}$ \\
\hline $1,2,3,4,7,8-\mathrm{HxCDF}$ & $18.7(15.6-23.9)$ & $2.3(2.0-3.2)$ & $<0.0001^{\mathrm{a}}$ \\
\hline $1,2,3,6,7,8-\mathrm{HxCDF}$ & $10.6(8.6-14.8)$ & $1.8(1.6-3.2)$ & $<0.0001^{\mathrm{a}}$ \\
\hline $1,2,3,7,8,9-\mathrm{HxCDF}$ & $0.5(0.3-0.7)$ & $0.14(0.11-0.16)$ & $<0.0001^{\mathrm{a}}$ \\
\hline $2,3,4,6,7,8-\mathrm{HxCDF}$ & $1.7(1.4-2.0)$ & $0.6(0.5-1.1)$ & $<0.0001^{\mathrm{a}}$ \\
\hline $1,2,3,4,6,7,8-\mathrm{HpCDF}$ & $19.8(11.5-26.5)$ & $2.0(1.4-3.1)$ & $<0.0001^{\mathrm{b}}$ \\
\hline $1,2,3,4,7,8,9-\mathrm{HpCDF}$ & $2.1(1.2-2.6)$ & $0.2(0.1-0.3)$ & $<0.0001^{\mathrm{a}}$ \\
\hline OCDF & $1.3(0.4-3.1)$ & $0.3(0.2-0.5)$ & $0.005^{\mathrm{b}}$ \\
\hline \multicolumn{4}{|l|}{ TEQs (pg/g lipid) } \\
\hline PCDDs TEQ & $9.7(6.4-12.6)$ & $3.3(2.6-3.6)$ & $<0.001^{\mathrm{b}}$ \\
\hline PCDFs TEQ & $5.8(4.8-7.4)$ & $1.9(1.6-2.3)$ & $<0.001^{\mathrm{a}}$ \\
\hline PCDDs + PCDFs TEQ & $16.1(12.5-18.4)$ & $5.2(4.2-6.0)$ & $<0.001^{\mathrm{a}}$ \\
\hline
\end{tabular}

Furthermore, when combining the two areas, the relationship between salivary cortisol, cortisone, or DHEA and dioxin TEQs in breast milk has an inverted-U shape, whereas estradiol and dioxin TEQs exhibit a U-shaped relationship. This is the first time that the level of salivary DHEA in a hot-spot has been found to be higher than that in a non-exposed area. The fact that this was not seen in previous studies $[22,23]$ could be due to the lower number of participants studied therein. DHEA is an inactive precursor steroid, which is secreted in large amounts by the adrenal gland in humans then converted into potent androgens and/or estrogens in peripheral tissues. We hypothesized that dioxin may inhibit some enzymes that convert DHEA into sex steroid hormones, thus resulting in a higher level of DHEA and a lower level of sex steroid hormones. The median level of estradiol, one of the most important sex hormones in women, found in this study is twice as high in the non-exposed area than in the hot-spot, although the difference is not significant $(p=0.063)$. Moran et al. [30] found that TCDD decreases estradiol levels in human luteinizing granulosa cells (hLGCs). However, this study only tested a TCDD concentration of $10 \mathrm{nM}$, which was insufficient for the dose-response model. In our study, the estradiol level decreased as the dioxin level increased up to $19 \mathrm{pg} / \mathrm{g}$ lipid, at which point the estradiol level also increased to give a U-shaped relationship.

Salivary cortisol, which is principally synthesized in the adrenal gland by ACTH regulation, is frequently used as a marker for adrenal function. Dioxins are known to accumulate in the adrenal gland [31] and to alter steroidogenesis [32]. The rate of cortisol biosynthesis depends on stimulation of the adrenal cortical cells by ACTH, although the precise mechanism by which dioxin stimulates cortisol and cortisone secretion via ACTH remains to be established. In this respect, Bestervel et al. [33] found that treatment of rat anterior pituitary with a wide range of TCDD concentrations $\left(0,10^{-19}, 10^{-17}, 10^{-15}, 10^{-13}\right.$, $\left.10^{-11}, 10^{-10}, 10^{-9} \mathrm{M}\right)$ increased ACTH synthesis and secretion. However, ACTH secretion decreased suddenly at TCDD concentrations higher than $10^{-9} \mathrm{M}$, thus giving the dose-response an inverted-U shape. The highest increase in secreted ACTH occurred between $10^{-13}$ and $10^{-10} \mathrm{M}$. These authors hypothesized that TCDD may increase ACTH concentrations by increasing the rate of transcription of the pro-opiomelanocortin (POMC) gene by an aryl hydrocarbon receptor (AhR)-mediated process. Likewise, Li and Wang [21] showed that dioxin-like PCB126 induced CYP21B, CYP11B1, and CYP11B2 mRNA expression, thereby increasing cortisol biosynthesis in human 
Table 3 Comparison of salivary steroid hormone levels between the two areas
Data are shown as median (inter-quartile range)

a Student's $t$-test

b Mann-Whitney $U$ test

\begin{tabular}{|c|c|c|c|c|c|}
\hline \multirow[t]{2}{*}{ Steroid hormones } & \multicolumn{2}{|c|}{ Hot-spot } & \multicolumn{2}{|c|}{ Non-exposed area } & \multirow[t]{2}{*}{$p$ value } \\
\hline & $n$ & Median & $n$ & Median & \\
\hline Cortisol (pg/ml) & 16 & 2795 (1525-4454) & 9 & $1605(580-2169)$ & $0.037^{\mathrm{a}}$ \\
\hline Cortisone (pg/ml) & 16 & $14221(10638-20734)$ & 9 & $8000(3101-14550)$ & $0.021^{\mathrm{a}}$ \\
\hline Cortisol/cortisone & 16 & $0.18(0.14-0.23)$ & 9 & $0.15(0.1-0.24)$ & $0.311^{\mathrm{a}}$ \\
\hline DHEA (pg/ml) & 15 & $152(141-273)$ & 9 & $79(39-166)$ & $0.029^{\mathrm{a}}$ \\
\hline Androstenedione $(\mathrm{pg} / \mathrm{ml})$ & 16 & $44.5(31.4-52.4)$ & 9 & $51.5(27.1-75.6)$ & $0.456^{\mathrm{a}}$ \\
\hline Estradiol (pg/ml) & 16 & $0.23(0.18-0.30)$ & 5 & $0.52(0.25-0.55)$ & $0.063^{\mathrm{b}}$ \\
\hline Progesterone (pg/ml) & 15 & $1.9(1.4-2.6)$ & 8 & $1.0(0.7-2.4)$ & $0.232^{\mathrm{b}}$ \\
\hline Testosterone $(\mathrm{pg} / \mathrm{ml})$ & 15 & $4.2(2.7-6.1)$ & 9 & $4.3(2.9-6.1)$ & $0.863^{\mathrm{a}}$ \\
\hline
\end{tabular}

adrenocortical H295R cells. These authors also speculated that high PCB126 levels may sensitize the regulation of ACTH in adrenocortical cells by increasing ACTH receptor levels. In a similar study, Shridhar et al. [34] studied the effect of TCDD on monkeys by administering a daily dose of $0,1,5$, or $25 \mathrm{ng}$ of TCDD and measuring the level of cortisol in serum after 1 year. They found that cortisol levels were significantly increased by TCDD [41.8 \pm 1.2 (control) vs. $52.9 \pm 2.2(1 \mathrm{ng})$ and $51.6 \pm 3.0 \mathrm{mg} / \mathrm{dl}$ $(5 \mathrm{ng}) ; p=0.01]$. Cortisol measurements in the 25-ng dose group were restricted to only two animals (68.1 and $31.5 \mathrm{mg} / \mathrm{dl}$ ) because of a lack of serum. In our study, the level of cortisol increased with TEQ dioxin level. However, when the TEQ dioxin level became high and continued to increase, the cortisol level tended to decrease, which resulted in an inverted-U relationship.

Cortisone is an inactive form of cortisol, which is converted to the former in the salivary gland by $11 \beta$ hydroxysteroid dehydrogenase type 2 [35]. Salivary cortisone was also found to be significantly higher in the hot-spot, although the cortisol/cortisone ratio did not differ significantly between the two areas. Thus, dioxin is not thought to affect this conversion enzyme.

Dioxin may exhibit non-traditional dose-response curves, such as inverted U-shaped or U-shaped curves in which an initial increase or decrease is followed by a subsequent reversal. Studies on Ranch Hand veterans have shown that TCDD is inversely associated with benign prostatic hyperplasia (BPH) in the low TCDD range. However, the risk of BHP diagnosis increases in the highest TCDD quartile [36]. In a related study of the relationship between serum TCDD and age at menopause, Eskenazi et al. [37] found a non-monotonic dose-related association with increasing risk of earlier menopause up to about 100 ppt TCDD, but not above. Studies involving other endocrine disruptors have also shown similar nonmonotonic dose-response relationships [38]. Thus, male mice exposed to a low dose of estradiol or diethylstilbestrol during the fetal period were found to have an enlarged prostate in adult life, although the opposite effect was observed at high doses [39].

In this study we chose saliva as the matrix for steroid hormones for several reasons. Thus, hormones exist in one of two forms - free and protein-bound-although only free hormones are biologically active, or bio-available. Steroid hormone levels in saliva are known to be well correlated with total free serum steroid hormone, thus making these levels a good indicator of total serum hormone as they reflect bioactivity [40]. Moreover, saliva is non-invasive and easy to collect and store in epidemiological studies.

Liquid chromatography tandem mass spectrometry (LC-MS/MS) is considered to be the best method for analyzing steroid hormones due to its high sensitivity and specificity compared with immunoassay. Furthermore, this technique can also be used to perform multiple analyses with a small sample volume [41]. Likewise, the use of an electrospray ionization source (ESI) with new derivatization methods [26, 27] allows us to increase the quantification sensitivity when measuring these steroid hormones.

All primiparae in this study were breastfeeding infants aged between 4 and 16 weeks. Although progesterone and estrogen are known to change during the menstrual cycle [42], full or nearly full breastfeeding can suppress menstruation and cause lactation-related amenorrhea [43], thereby minimizing the fluctuation of those steroid hormones.

As salivary cortisol hormone is known to be circadian, all samples were collected in the morning between 8 and 10 AM. All subjects were asked about diseases related to hormone metabolism but none reported having such diseases or to be taking medication at the time of the study. As the steroid hormone levels of one participant from the nonexposed area were abnormally high, this participant was excluded from the analysis.

This study had some limitations which need to be considered. Firstly, although we asked our local staff to increase the number of subjects, there were very few primiparae available in the study areas. Thus, although there were 120 lactating mothers in both areas together, 
Fig. 2 Relationship between dioxin levels in breast milk and salivary steroid hormones

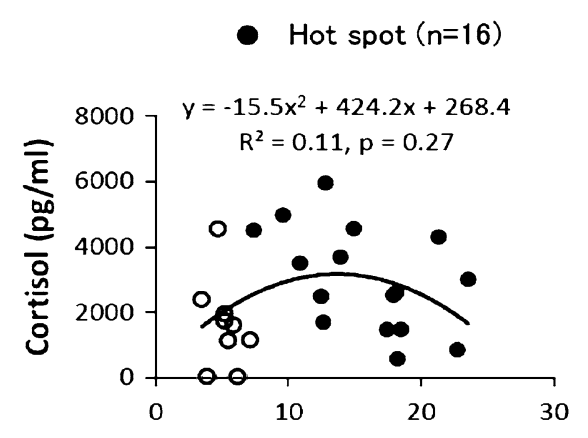

TEQ PCDDs + PCDFs (pg/g lipid)
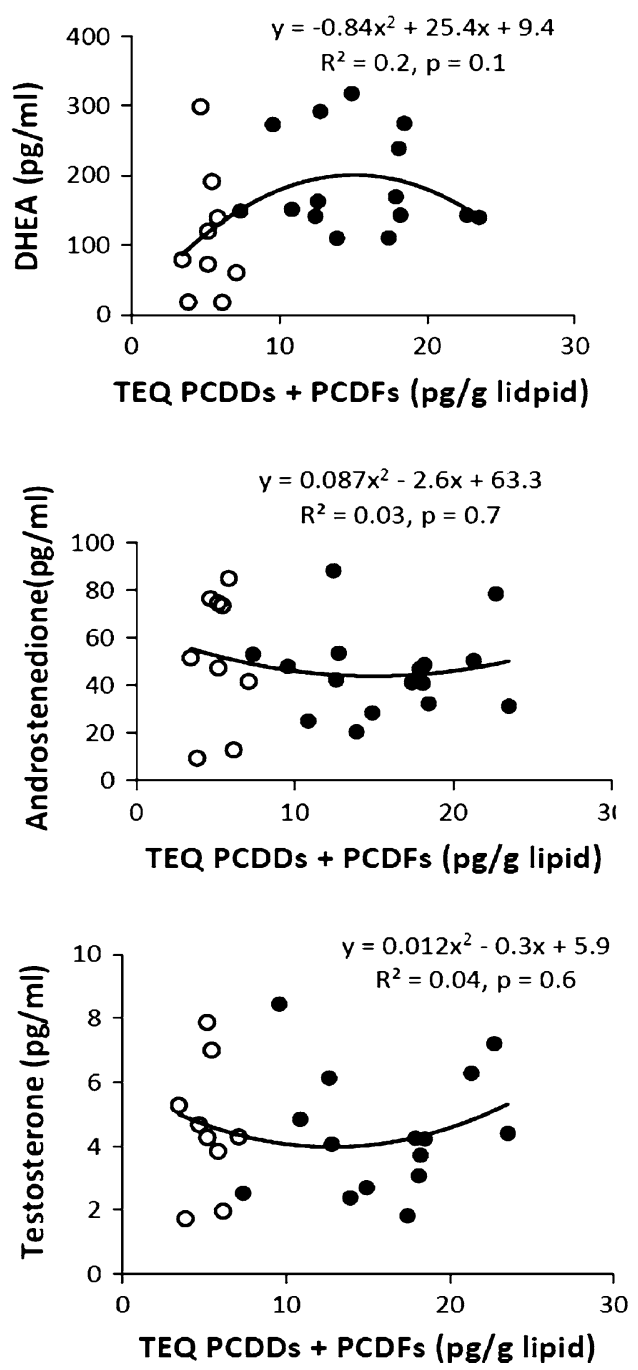

Non-exposed area $(n=9)$

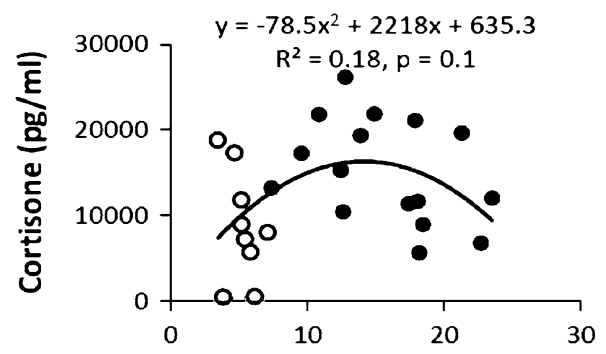

TEQ PCDDs + PCDFs (pg/g lipid)
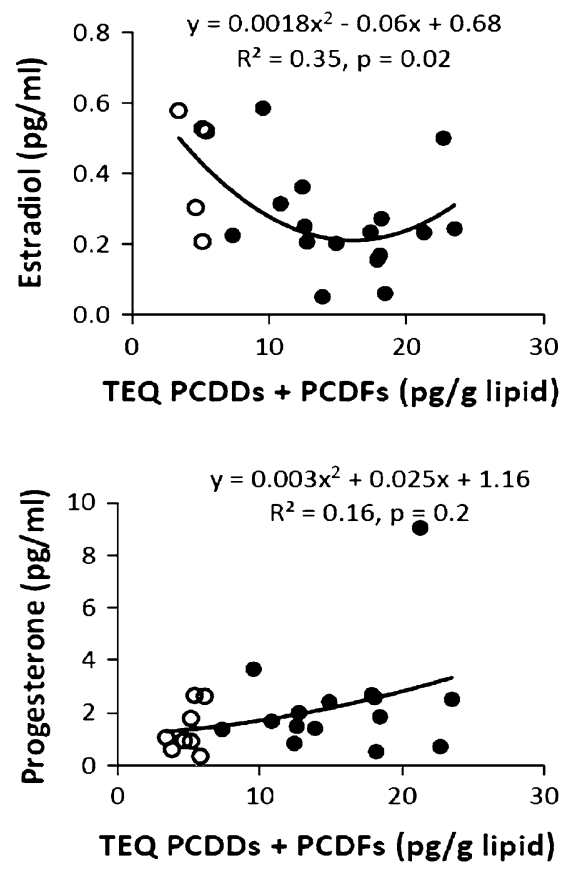

only 26 of these were primiparae, thereby limiting the sample size. Secondly, cortisol is a stress hormone and, as such, could be affected by many factors, such as socioeconomic status, psychological stress, and temperature. Although we cannot adjust for these factors, they are unlikely to differ significantly between the areas, thus meaning that their effect on the results is probably minimal. Thirdly, as this study was carried out 40 years after herbicide use, the concentration of dioxins, especially TCDD, has decreased markedly, thus limiting the dioxin distribution and therefore the dose-effect range. Fourthly, dioxin in blood was not analyzed as we were unable to collect a sufficient volume of blood from individual Vietnamese. Although we can analyze pooled samples, it does not allow us to evaluate the correlation in individuals. However, as we know dioxin levels in blood are well- 
correlated with the corresponding levels in breast milk [44], breast milk could be a good matrix for evaluating dioxin body burden.

In conclusion, this is the first study to examine the relationship between dioxins and steroid hormone levels in Vietnam. The fact that a higher level of salivary steroid hormones, including cortisol, cortisone, and DHEA, was found in the hot-spot area reflects the effects of dioxin on adrenal function. However, these steroid hormone levels decreased at high dioxin levels, thus resulting in an inverted-U shaped relationship between the two. In contrast, estradiol exhibited a U-shaped relationship with dioxin levels. Although our results highlight the effects of dioxin on salivary steroid hormone levels in Vietnamese primiparae, follow-up studies involving a larger number of subjects are nevertheless required to confirm these findings.

Acknowledgments The authors thank all mothers in Kim Bang and Phu Cat who participated in this study. The study was supported by a Japan Society for the Promotion of Science, Grant-in-Aid for Scientific Research (A) 19209021.

Conflict of interest The authors declare they have no conflict of interest.

\section{References}

1. Diamanti-Kandarakis E, Bourguignon JP, Giudice LC, Hauser R, Prins GS, Soto AM, et al. Endocrine-disrupting chemicals: an endocrine society scientific statement. Endocr Rev. 2009;30:293-342.

2. Soto AM, Sonnenschein C. Environmental causes of cancer: endocrine disruptors as carcinogens. Nat Rev Endocrinol. 2010;6:363-70.

3. Hooper K. Breast milk monitoring programs (BMMPs): worldwide early warning system for polyhalogenated POPs and for targeting studies in children's environmental health. Environ Health Perspect. 1999;107:429-30.

4. Stellman JM, Stellman SD, Christian R, Weber T, Tomasallo C. The extent and patterns of usage of Agent Orange and other herbicides in Vietnam. Nature. 2003;422:681-7.

5. Dwernychuk LW, Cau HD, Hatfield CT, Boivin TG, Hung TM, Dung PT, et al. Dioxin reservoirs in southern Viet Nam-a legacy of Agent Orange. Chemosphere. 2002;47:117-37.

6. Nhu DD, Kido T, Naganuma R, Sawano N, Tawara K, Nishijo M, et al. A GIS study of dioxin contamination in a Vietnamese region sprayed with herbicide. Environ Health Prev Med. 2009;14:353-60.

7. Tai PT, Nishijo M, Kido T, Nakagawa H, Maruzeni S, Naganuma $\mathrm{R}$, et al. Dioxin concentrations in breast milk of Vietnamese nursing mothers: a survey four decades after the herbicide spraying. Environ Sci Technol. 2011;45:6625-32.

8. Saito K, Nhu DD, Suzuki H, Kido T, Naganuma R, Sakakibara C, et al. Association between dioxin concentrations in breast milk and food group intake in Vietnam. Environ Health Prev Med. 2010;15:48-56.

9. Dwernychuk LW. Dioxin hot spots in Vietnam. Chemosphere. 2005;60:998-9.

10. Dwernychuk LH, Hung TM, Boivin TG, Bruce GS, Dung PT, Son LK, et al. The Agent Orange dioxin issue in Vietnam: a manageable problem. Organohalogen Compd. 2006;68:312-5.
11. Mai TA, Doan TV, Tarradellas J, de Alencastro LF, Grandjean D. Dioxin contamination in soils of Southern Vietnam. Chemosphere. 2007;67:1802-7.

12. Schecter A, Dai LC, Thuy LT, Quynh HT, Minh DQ, Cau HD, et al. Agent Orange and the Vietnamese: the persistence of elevated dioxin levels in human tissues. Am J Public Health. 1995;85:516-22.

13. Schecter A, Dai LC, Papke O, Prange J, Constable JD, Matsuda $\mathrm{M}$, et al. Recent dioxin contamination from Agent Orange in residents of a southern Vietnam city. J Occup Environ Med. 2001;43:435-43.

14. Schecter A, Pavuk M, Constable JD, Dai le Papke O C, Papke O. A follow-up: high level of dioxin contamination in Vietnamese from agent orange, three decades after the end of spraying. J Occup Environ Med. 2002;44:218-20.

15. Schecter A, Quynh HT, Pavuk M, Papke O, Malisch R, Constable JD. Food as a source of dioxin exposure in the residents of Bien Hoa City, Vietnam. J Occup Environ Med. 2003;45:781-8.

16. Steenland K, Piacitelli L, Deddens J, Fingerhut M, Chang LI. Cancer, heart disease, and diabetes in workers exposed to 2,3,7,8tetrachlorodibenzo- $p$-dioxin. J Natl Cancer Inst. 1999;91:779-86.

17. Henriksen GL, Ketchum NS, Michalek JE, Swaby JA. Serum dioxin and diabetes mellitus in veterans of Operation Ranch Hand. Epidemiology. 1997;8:252-8.

18. Mocarelli P, Gerthoux PM, Ferrari E, Patterson DG Jr, Kieszak SM, Brambilla $\mathrm{P}$, et al. Paternal concentrations of dioxin and sex ratio of offspring. Lancet. 2000;355:1858-63.

19. Bookstaff RC, Moore RW, Peterson RE. 2,3,7,8-tetrachlorodibenzo-p-dioxin increases the potency of androgens and estrogens as feedback inhibitors of luteinizing hormone secretion in male rats. Toxicol Appl Pharmacol. 1990;104:212-24.

20. Bestervelt LL, Cai Y, Piper DW, Nolan CJ, Pitt JA, Piper WN. TCDD alters pituitary-adrenal function. I: adrenal responsiveness to exogenous ACTH. Neurotoxicol Teratol. 1993;15:365-7.

21. Li LA, Wang PW. PCB126 induces differential changes in androgen, cortisol, and aldosterone biosynthesis in human adrenocortical H295R cells. Toxicol Sci. 2005;85:530-40.

22. Nhu DD, Kido T, Naganuma R, Suzuki H, Kuroda N, Honma S, et al. Salivary cortisol and cortisone levels, and breast milk dioxin concentrations in Vietnamese primiparas. Toxicol Environ Chem. 2010;92:1939-52.

23. Nhu DD, Kido T, Hung NN, Thom LT, Naganuma R, Son LK, et al. Dioxin levels in the breast milk and estradiol and androgen levels in the saliva of Vietnamese primiparae. Toxicol Environ Chem. 2011;93:824-38.

24. Young AL. The history, use, disposition and environmental fate of Agent Orange. New York: Springer; 2009.

25. Matsui F, Koh E, Yamamoto K, Sugimoto K, Sin HS, Maeda Y, et al. Liquid chromatography-tandem mass spectrometry (LC-MS/MS) assay for simultaneous measurement of salivary testosterone and cortisol in healthy men for utilization in the diagnosis of late-onset hypogonadism in males. Endocr $\mathrm{J}$. 2009;56:1083-93.

26. Arai S, Miyashiro Y, Shibata Y, Kashiwagi B, Tomaru Y, Kobayashi M, et al. New quantification method for estradiol in the prostatic tissues of benign prostatic hyperplasia using liquid chromatography-tandem mass spectrometry. Steroids. 2010;75: 13-9.

27. Yamashita K, Miyashiro Y, Maekubo H, Okuyama M, Honma S, Takahashi M, et al. Development of highly sensitive quantification method for testosterone and dihydrotestosterone in human serum and prostate tissue by liquid chromatography-electrospray ionization tandem mass spectrometry. Steroids. 2009;74:920-6.

28. Tawara K, Nishijo M, Maruzeni S, Nakagawa H, Kido T, Naganuma R, et al. Residual congener pattern of dioxins in human breast milk in southern Vietnam. Chemosphere. 2011;84:979-86. 
29. Van den Berg M, Birnbaum LS, Denison M, De Vito M, Farland W, Feeley M, et al. The 2005 World Health Organization reevaluation of human and mammalian toxic equivalency factors for dioxins and dioxin-like compounds. Toxicol Sci. 2006;93:223-41.

30. Moran FM, Conley AJ, Corbin CJ, Enan E, VandeVoort C, Overstreet JW, et al. 2,3,7,8-tetrachlorodibenzo-p-dioxin decreases estradiol production without altering the enzyme activity of cytochrome P450 aromatase of human luteinized granulosa cells in vitro. Biol Reprod. 2000;62:1102-8.

31. Weber LW, Ernst SW, Stahl BU, Rozman K. Tissue distribution and toxicokinetics of 2,3,7,8-tetrachlorodibenzo-p-dioxin in rats after intravenous injection. Fundam Appl Toxicol. 1993;21:523-34.

32. DiBartolomeis MJ, Williams C, Jefcoate CR. Inhibition of ACTH action on cultured bovine adrenal cortical cells by 2,3,7,8-tetrachlorodibenzo-p-dioxin through a redistribution of cholesterol. J Biol Chem. 1986;261:4432-7.

33. Bestervelt LL, Pitt JA, Nolan CJ, Cai Y, Piper DW, Dybowski JA, et al. In vitro 2,3,7,8-tetrachlorodibenzo-p-dioxin interference with the anterior pituitary hormone adrenocorticotropin. Toxicol Sci. 1998;44:107-15.

34. Shridhar S, Farley A, Reid RL, Foster WG, Van Vugt DA. The effect of 2,3,7,8-tetrachlorodibenzo- $p$-dioxin on corticotrophinreleasing hormone, arginine vasopressin, and pro-opiomelanocortin mRNA levels in the hypothalamus of the cynomolgus monkey. Toxicol Sci. 2001;63:181-8.

35. Whorwood CB, Mason JI, Ricketts ML, Howie AJ, Stewart PM. Detection of human 11 beta-hydroxysteroid dehydrogenase isoforms using reverse-transcriptase-polymerase chain reaction and localization of the type 2 isoform to renal collecting ducts. Mol Cell Endocrinol. 1995;110:R7-12.
36. Gupta A, Ketchum N, Roehrborn CG, Schecter A, Aragaki CC, Michalek JE. Serum dioxin, testosterone, and subsequent risk of benign prostatic hyperplasia: a prospective cohort study of Air Force veterans. Environ Health Perspect. 2006;114:1649-54.

37. Eskenazi B, Warner M, Marks AR, Samuels S, Gerthoux PM, Vercellini $P$, et al. Serum dioxin concentrations and age at menopause. Environ Health Perspect. 2005;113:858-62.

38. Welshons WV, Thayer KA, Judy BM, Taylor JA, Curran EM, vom Saal FS. Large effects from small exposures. I. Mechanisms for endocrine-disrupting chemicals with estrogenic activity. Environ Health Perspect. 2003;111:994-1006.

39. vom Saal FS, Timms BG, Montano MM, Palanza P, Thayer KA, Nagel SC, et al. Prostate enlargement in mice due to fetal exposure to low doses of estradiol or diethylstilbestrol and opposite effects at high doses. Proc Natl Acad Sci USA. 1997;94:2056-61.

40. Lewis JG. Steroid analysis in saliva: an overview. Clin Biochem Rev. 2006;27:139-46.

41. Soldin SJ, Soldin OP. Steroid hormone analysis by tandem mass spectrometry. Clin Chem. 2009;55:1061-6.

42. Gandara BK, Leresche L, Mancl L. Patterns of salivary estradiol and progesterone across the menstrual cycle. Ann NY Acad Sci. 2007;1098:446-50.

43. Gray RH, Campbell OM, Apelo R, Eslami SS, Zacur H, Ramos $\mathrm{RM}$, et al. Risk of ovulation during lactation. Lancet. 1990;335:25-9.

44. Todaka T, Hirakawa H, Kajiwara J, Hori T, Tobiishi K, Yasutake $\mathrm{D}$, et al. Relationship between the concentrations of polychlorinated dibenzo- $p$-dioxins, polychlorinated dibenzofurans, and polychlorinated biphenyls in maternal blood and those in breast milk. Chemosphere. 2010;78:185-92. 